\title{
The Ndc80 complex: integrating the kinetochore's many movements
}

\author{
John Tooley $\cdot$ P. Todd Stukenberg
}

Published online: 11 February 2011

(C) Springer Science+Business Media B.V. 2011

\begin{abstract}
The Ndc80 complex lies at the heart of the kinetochore, a large protein machine that accurately segregates chromosomes during cell division. The Ndc80 complex has structural roles in assembling the kinetochore, but also functions to congress chromosomes and to signal the spindle checkpoint. It directly binds to microtubules and is currently the best candidate for the long-sought protein that couples microtubule depolymerization to chromosome movement. A combination of structural and genetic data has recently converged to generate the first models for this fascinating motor activity. Additionally, recent data point to an increasingly dynamic role for $\mathrm{Ndc} 80$ in the kinetochore-one which involves not only simple binding to microtubules but also shifts in complex shape and its location within the overall kinetochore structure. In this review, we discuss recent advances in our understanding of the $\mathrm{Ndc} 80$ complex and address future areas of research.
\end{abstract}

Keywords kinetochore - microtubule $\cdot$ coupler . checkpoint $\cdot \mathrm{Ndc} 80$

Responsible Editors: James Wakefield and Herbert Macgregor

J. Tooley $\cdot$ P. T. Stukenberg $(\bowtie)$

Department of Biochemistry and Molecular Genetics, University of Virginia,

Charlottesville, VA 22908, USA

e-mail: pts7h@virginia.edu
Abbreviations
MT Microtubule
KT Kinetochore
CHD Calponin homology domain
SAC Spindle assembly checkpoint
RNAi RNA interference
EM Electron microscopy
KMN KNL-1/Mis12/Ndc80 complex
RZZ Rod/ZW10/Zwilch complex
ChIP Chromatin immunoprecipitation
AFM Atomic force microscopy

\section{Mitosis and kinetochores}

A mitotic spindle segregates replicated genomes into two daughter cells. Microtubules form the mitotic spindle and make bipolar attachments to each chromosome through complex protein machines known as kinetochores. Mammalian kinetochores are comprised of more than 100 proteins which coordinate numerous activities including nucleation and capture of microtubules, regulation of microtubule dynamics, powering and coordinating chromosome movements, and integrating cell cycle progression with kinetochore microtubule attachments (Musacchio and Salmon 2007; Cheeseman and Desai 2008; Tanaka and Desai 2008; Stukenberg and Foltz 2010). At the center of all of these activities is a kinetochore's ability to correctly link spindle microtubules to mitotic chromosomes. 
Classic in vitro experiments by Koshland et al. (1988) demonstrated that kinetochores could move isolated chromosomes on microtubules in the absence of ATP. These data suggested that chromosomes are not powered by traditional ATP-driven motors, but rather by the energy stored in the dynamically unstable microtubule. This model was rigorously debated since some of the first kinetochore proteins identified were kinesins and dynein (Wordeman et al. 1991; Yen et al. 1992). Current models now suggest that ATP-driven motors play important roles in generating bipolar kinetochore attachments and coordinating spindle checkpoint signaling. However, ATPdriven motors are not required to align most chromosomes or to segregate chromatids in anaphasereinvigorating the concept of depolymerizationcoupled movement (Howell et al. 2001; Putkey et al. 2002). Characterization of the Ndc80 complex in numerous model organisms has shown that this four-protein complex is essential for chromosome segregation in all eukaryotes. More importantly, it has a structure and activities consistent with a coupler that can harness the energy from a depolymerizing microtubule to perform the work of moving chromosomes.

\section{The early years-discovery and phenotypes}

Lee and colleagues first made the connection that proteins of the Ndc80 complex were critical for kinetochore movements. They isolated the Ndc80/ Hecl subunit in a two-hybrid screen with the retinoblastoma tumor suppressor and named the human protein Hec1 (for highly expressed in cancer 1; Chen et al. 1997). Using a monoclonal antibody against Hec1, they demonstrated that the protein localized to kinetochores. Injection of this antibody blocked mitotic chromosome movements in human cells. The budding yeast homolog was later identified as a contaminant in a spindle pole body preparation (Wigge et al. 1998). Since the phenotypes of temperature-sensitive mutants were similar to those of Ndc10, an established kinetochore protein, the budding yeast protein was named Ndc80. The budding yeast complex containing $\mathrm{Ndc} 80$ and three other tightly associated proteins was later purified. Two co-purifying proteins were believed to be members of the spindle pole complex and were named Spc25 and Spc24 (Wigge and Kilmartin 2001). The fourth protein, Nuf2, had previously been identified in a separate spindle pole body preparation (Osborne et al. 1994). While a role for these proteins at the spindle pole/centrosome is dubious, it is clear that all of the components of the $\mathrm{Ndc} 80$ complex are essential for kinetochore function in eukaryotes. All four proteins are able to ChIP to centromeres and are critical for chromosome segregation. The yeast $\mathrm{Ndc} 80$ complex also is required to generate the spindle checkpoint signal (Janke et al. 2001).

Discovery of the vertebrate complex soon followed in a flurry of papers. These papers established that the four-protein Ndc80 kinetochore complex is conserved from yeast to humans and that the complex is highly elongated, consistent with its predicted coiled-coil structure (Deluca et al. 2002, 2003, 2004; MartinLluesma et al. 2002; Desai et al. 2003; Hori et al. 2003; McCleland et al. 2003, 2004; Bharadwaj et al. 2004). It is required for chromosome movements and kinetochore microtubule attachments in all species. The vertebrate complex also is required to generate spindle checkpoint signals, although the requirement is highly sensitive to the degree of knockdown and shows some species variability. Early experiments further demonstrated that the complex plays a structural role in the kinetochore, as a number of outer kinetochore proteins could not properly assemble on kinetochores following Ndc80 knockdown (McCleland et al. 2003, 2004; Hanisch et al. 2006; Ciferri et al. 2007; Ohta et al. 2010). This made it impossible to assign a direct role for the complex in the strong phenotypes generated by its knockdown. Later rescue experiments using separation of function mutants of the $\mathrm{Ndc} 80 / \mathrm{Hec} 1$ subunit established that the complex does indeed play a direct role in facilitating chromosome movements (Guimaraes et al. 2008; Miller et al. 2008).

\section{Structure and function studies}

Hydrodynamic analysis and biochemical reconstitution of the Saccharomyces cerevisiae, Caenorhabditis elegans, Xenopus laevis, and human $\mathrm{Ndc} 80$ complexes opened the door to advances in our understanding of complex structure. The Ndc80 complex exists in a 1:1:1:1 stoichiometry with a calculated molecular weight of $\sim 170-190 \mathrm{kDa}$ (McCleland et al. 
2004; Ciferri et al. 2005, 2008; Wei et al. 2005, 2007; Cheeseman et al. 2006). All four complex members co-purify with high affinity in vitro, suggesting a tight interaction (Wigge and Kilmartin 2001; Cheeseman et al. 2004; McCleland et al. 2004). Rotary shadow electron microscopy (EM) and atomic force microscopy demonstrated that the $\mathrm{Ndc} 80$ complex contains two globular domains at either end of a $\sim 57-\mathrm{nm}$ highly elongated coiled-coil (Ciferri et al. 2005, 2008; Wei et al. 2005, 2006). The extended shape of the complex leaves it capable of spanning the distance between the electron-dense inner and outer regions of the kinetochore (Cleveland et al. 2003). At one end of the complex, the globular domains of Spc24 and Spc25 dimerize to form a "receptor" connecting the Ndc80 complex to more centromereproximal elements of the kinetochore (Wei et al. 2006; Petrovic et al. 2010). At the other end of the complex, the Ndc80/Hec1 and Nuf2 globular domains dimerize to form a dual calponin homology domain (CHD; Wei et al. 2007; Ciferri et al. 2008), a protein fold found in other microtubule and actinbinding proteins (Sjoblom et al. 2008). The Ndc80/ $\mathrm{Hec} 1$ protein also contains an unstructured tail at its $\mathrm{N}$-terminus that ranges from 80 to 112 amino acids, depending on the species. The two globular domains are connected by the coiled-coil regions contributed by each protein. These regions allow the two dimers to tetramerize and to form the dumb-bell shape that characterizes this complex (Ciferri et al. 2008). The coiled region of the $\mathrm{Ndc} 80 / \mathrm{Hecl}$ protein is interrupted by an unstructured "hinge" region which allows the central shaft to bend in vitro (Wang et al. 2008) and is postulated to also permit complex flexibility in vivo (Wan et al. 2009; Fig. 1).

The microtubule binding activity of the Ndc 80 complex resides in the Ndc80/Nuf2 globular region. There is a bipartite microtubule binding motif, as both the N-terminal tail and the CHD of Ndc80/Hec1 can bind microtubules in vitro, and each contributes to the overall binding affinity (Cheeseman et al. 2006; Wei et al. 2007; Ciferri et al. 2008; Miller et al. 2008). It is currently unclear if the Nuf2 CHD contacts microtubules or simply regulates the $\mathrm{Ndc} 80 / \mathrm{Hec} 1 \mathrm{CHD}$ (Wilson-Kubalek et al. 2008; Alushin et al. 2010). One possible role of the Nuf2 CHD could be to form a dual CHD within the Ndc80 complex. A single Hec1 CHD cannot bind microtubules in vitro while the unstructured tail can (Miller et al. 2008). It is only when the Ndc80/Hec1 CHD is paired with the Nuf2 CHD that microtubule binding occurs. A similar effect is seen with the plus-end microtubule binding protein EB1, which cannot bind microtubules effectively unless dimerized (Zimniak et al. 2009). Dual CHD requirements also exist for actin-binding proteins such as $\alpha$-actinin (Sjoblom et al. 2008).

\section{The Ndc80 complex as a kinetochore coupler}

A depolymerization-based coupler must use microtubule shortening to both power cargo movement and to provide directionality. A key to understanding how kinetochores act as couplers will be a careful

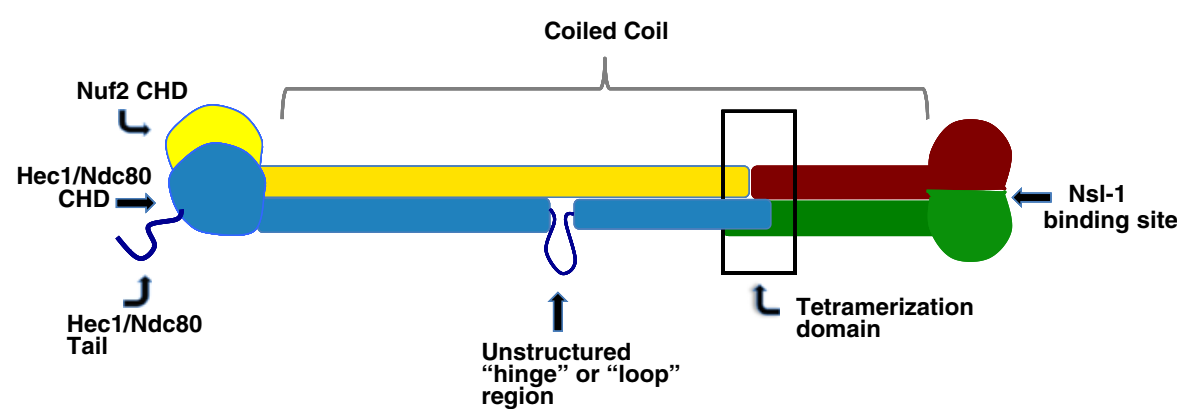

Fig. 1 Structure of the Ndc80 complex. The four-member Ndc80 complex consists of $\mathrm{Ndc} 80 / \mathrm{Hec} 1, \mathrm{Nuf} 2, \mathrm{Spc} 25$, and Spc24. The highly elongated complex has a calculated molecular weight of $170-190 \mathrm{kDa}$ and a length of $\sim 57 \mathrm{~nm}$. The globular N-terminal domains of $\mathrm{Ndc} 80 / \mathrm{Hecl}$ (blue) and Nuf2 (yellow) form a dual calponin homology domain (CHD), and the $\mathrm{Ndc} 80 / \mathrm{Hec} 1$ subunit also contains an unstructured tail at its N-terminus (dark blue). The globular C-terminal domains of Spc25 (green) and Spc24 (red) dimerize to form a "receptor" connecting to the Nsl-1 subunit of the Mis12 complex. The long coiled-coils contributed by each of the four proteins join together in the tetramerization domain (black box). The Ndc80/ Hec1 subunit also contains an unstructured "hinge" region (dark blue) that permits complex flexibility in vitro 
description of how they engage microtubules. The $\mathrm{Ndc} 80$ complex is currently the best candidate for this elusive coupling activity. The Ndc 80 complex directly binds microtubules in vitro with $\sim 0.5-3 \mu \mathrm{M}$ affinity (Cheeseman et al. 2006; Ciferri et al. 2008). When recombinant Ndc80 complex is attached to polystyrene beads, the coated beads are capable of binding the lateral sides of stabilized microtubules, remaining attached to the plus end of a microtubule in response to tension, and tracking with a depolymerizing microtubule (McIntosh et al. 2008; Powers et al. 2009). These data argue that Ndc80 is a kinetochore coupler capable of moving a large cargo in vitro. In vivo, mutants of the $\mathrm{Ndc} 80 / \mathrm{Hec} 1$ subunit generate kinetochores that are unable to productively bind microtubules, congress chromosomes to the metaphase plate, or segregate them during anaphase (Guimaraes et al. 2008; Miller et al. 2008). Injection of a monoclonal antibody targeting $\mathrm{Ndc} 80 / \mathrm{Hec} 1$ results in greater stretch between sister kinetochores, loss of K-fiber flux, and the inability of kinetochores to release microtubules (Deluca et al. 2006). Thus, the in vivo data corroborate what is seen in vitro and point toward a direct role for the $\mathrm{Ndc} 80$ complex in depolymerization-coupled movement.

The unstructured tails of tubulin contribute significantly to the binding affinity of the Ndc80/Hec1 subunit (Ciferri et al. 2008; Miller et al. 2008). These negatively charged $\mathrm{C}$-terminal tails (often referred to as E-hooks) interact with the $\mathrm{Ndc} 80 / \mathrm{Hec1}$ tail, which contains numerous positively charged residues. Electrostatic interactions between the two tails are thought to be a primary mode of Ndc80 complex binding. Cryo-EM images reveal that the $\mathrm{Ndc} 80 / \mathrm{Hec} 1 \mathrm{CHD}$ contacts the microtubule directly, and mutations in residues which contact the microtubule greatly reduce binding affinity in vitro (Cheeseman et al. 2006; Ciferri et al. 2008; Wilson-Kubalek et al. 2008; Alushin et al. 2010). This suggests that the interaction between the Ndc80 complex and a microtubule is bipartite and is generated by a combination of binding affinity from the CHD and the unstructured tail. The CHD also requires E-hooks for maximal binding (our unpublished data), suggesting a dual role for these unstructured tails of tubulin.

The cryo-EM structure of a chimeric version of the human complex has been solved to a resolution of 8.6 $\AA$. This higher-resolution structure allowed the visualization of Ndc80 secondary structure and facilitated the unambiguous docking of the "Bonsai" crystal structure within the cryo-EM density (Alushin et al. 2010). An important finding from this study was the identification of a binding interface between the Ndc80 complex and a microtubule. The structure shows a small set of surface residues on the Hecl CHD (referred to as the "toe") that bind a conserved surface spanning the $\alpha-\beta$ or $\beta-\alpha$ subunit interface on the lateral surface of a stabilized microtubule. Interestingly, we have characterized a point mutant in this "toe" region of the Hecl CHD, which renders kinetochores highly defective in assays for depolymerizationcoupled movement and generation of productive microtubule attachments (our unpublished data). Thus, the biochemistry and the genetics of the Ndc80 complex have converged to argue very strongly that the $\mathrm{Ndc} 80$ complex is a direct mediator of force production in human cells. It is difficult to identify the density of the E-hooks in the cryo-EM structures, but we have identified additional lysine residues in the Hec1 CHD that lie close to the exit point of the E-hooks (Alushin et al. 2010). These lysines also are essential for metaphase congression of chromosomes (our unpublished data), strongly arguing that E-hooks also interact with the Hec1 CHD to generate additional coupling forces.

In vitro binding experiments using recombinant Ndc80 complex have demonstrated a cooperative aspect to Ndc80 binding (Cheeseman et al. 2006; Ciferri et al. 2008; Alushin et al. 2010). Metazoan Ndc80 complex has a much higher affinity for another Ndc 80 on a microtubule than a free microtubule, but such cooperativity is not seen in the budding yeast complex. The tail of $\mathrm{Ndc} 80 / \mathrm{Hec} 1$ is thought to be responsible for driving cooperativity, since in its absence cooperative binding is lost. Cooperativity could come from tail-tail interactions (since the Hec1 tail alone shows cooperative binding characteristics; Miller et al. 2008) and/or from interactions with the negatively charged regions on adjacent $\mathrm{Ndc} 80$ complexes (such as those that reside in the $\mathrm{Ndc} 80 / \mathrm{Hecl}$ or Nuf2 CHDs; Ciferri et al. 2008). These interactions between dual CHDs of adjacent complexes may also be coordinated by the unstructured tail (Alushin et al. 2010). In vitro cross-linking and MS/MS studies have identified interactions between residues in the Hecl tail and residues in both the Hec1 and Nuf2 CHDs (Maiolica et al. 2007). Furthermore, mutating seven serines in the Hec1 tail to aspartic acid (mimicking 
phosphorylation) diminishes Ndc80 complex cluster formation (Alushin et al. 2010). Thus, the unstructured tail of metazoan $\mathrm{Ndc} 80 / \mathrm{Hecl}$ appears to have two functions: first, to increase the affinity for tubulin and second, to modulate cooperativity. These data argue for a model of depolymerization-based coupling where groups of Ndc 80 work on a single tubulin protofilament. Current models suggest that rather than slide ahead of a depolymerizing end, the "toe" of the most proximal Ndc80 complex releases in response to protofilament curvature. Following its release, the most attractive binding site for that $\mathrm{Ndc} 80$ complex would be behind the last subunit on the straight protofilament (Fig. 2).

Despite convincing in vitro data, the in vivo contributions of cooperativity remain in question. The $\mathrm{Ndc} 80 / \mathrm{Hec} 1$ tail is critical for kinetochore function in vertebrates but dispensable in budding yeast (Guimaraes et al. 2008; Miller et al. 2008; Kemmler et al. 2009; D. Burke unpublished data). Moreover, diverse organisms build kinetochores containing roughly the same number of Ndc80 complexes per microtubule (6-9; Joglekar et al. 2006, 2008; Johnston et al. 2010). Current published data make it unclear whether the essential vertebrate activity of the tail stems from its microtubule binding activities or the regulation of cooperative binding. We are currently characterizing a separation of function mutant that suggests that cooperativity is not absolutely required for congression of chromosomes to the metaphase plate (our unpublished data). We cannot rule out more subtle roles for cooperativity, such as enhancing rates of chromosome movement. Nevertheless, our data argue that the cooperativity model shown in Fig. 2 is not an absolute requirement for chromosome congression.

\section{Regulation of the Ndc80 complex}

The interaction between the $\mathrm{Ndc} 80$ complex and microtubules is highly regulated. The best-studied

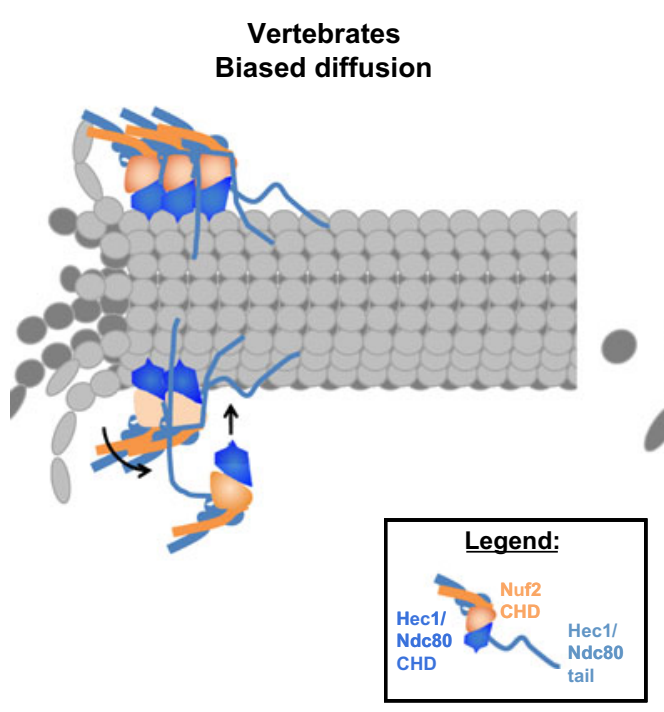

Budding yeast Sliding Clamp

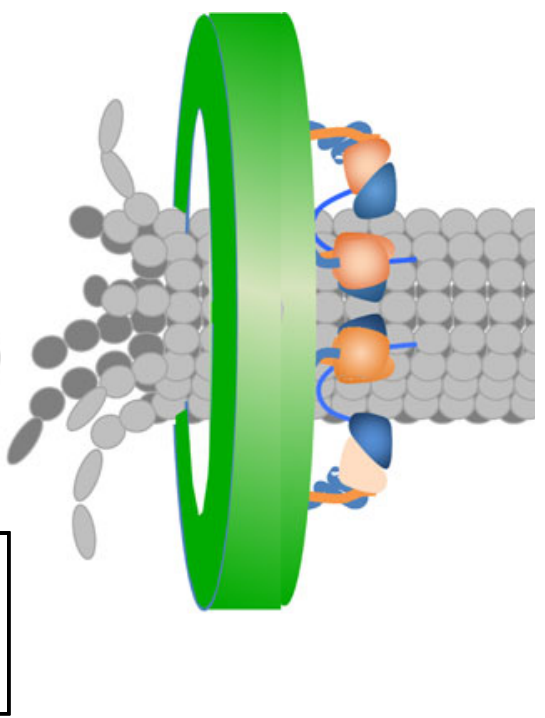

Fig. 2 Models for depolymerization-coupled movement. A vertebrate kinetochore uses the $\mathrm{Ndc} 80$ complex to couple to depolymerizing microtubule through biased diffusion. The "toe" region of the $\mathrm{Ndc} 80 / \mathrm{Hecl} \mathrm{CHD}$ reacts to the conformational state of the microtubule lattice, binding to straight tubulin protofilaments between two subunits but becomes dislodged from depolymerizing tubulin subunits (adapted from Alushin et al. 2010). Following displacement of the $\mathrm{CHD}$ toe, the $\mathrm{Ndc} 80 / \mathrm{Hec} 1$ tail acts as a sliding tether, allowing the kinetochore to retain partial connection to the microtubule through electrostatic interactions with the charged tubulin E-hooks (first arrow). The displaced Ndc80 complex then undergoes biased diffusion and rebinds at the next available tubulin subunit (second arrow) - a process that may be aided by cooperative binding of $\mathrm{Ndc} 80$ complexes. Budding yeast, in contrast, make use of a dual coupler involving both the Ndc80 complex and also the Dam1 ring complex to slide behind a depolymerizing microtubule. Here, the Dam1 complex would be able to ride the conformational wave created at the microtubule plus end during depolymerization 
mode of Ndc80 regulation remains phosphorylation by the mitotic kinase Aurora B/Ipl1. The catalytic member of the four-member chromosomal passenger complex (CPC; Ruchaud et al. 2007), Aurora B/Ipl1 phosphorylates $\mathrm{Ndc} 80 / \mathrm{Hec} 1$ in vitro and in vivo on a number of sites contained in its N-terminal unstructured tail (Cheeseman et al. 2002, 2006; Deluca et al. 2006; Guimaraes et al. 2008; Akiyoshi et al. 2009; Welburn et al. 2010). According to current models, phosphorylation of $\mathrm{Ndc} 80 / \mathrm{Hec} 1$ occurs in response to the presence of an aberrant microtubule connection, such as a syntelic or merotelic attachment. As kinetochore interactions with a microtubule strengthen, kinetochores come under tension, and the Ndc80 complex is stretched away from the inner centromere, where Aurora B resides (Liu et al. 2009; Welburn et al. 2010). In support of this, artificially tethering Aurora B kinase to the outer kinetochore causes kinetochores to be displaced from microtubules (Liu et al. 2009). As the interaction between the Ndc80/ Hec1 tail and tubulin E-hooks is driven by charge (Miller et al. 2008), the addition of negatively charged phosphates to the highly basic tail region of Ndc80/ Hec1 (net charge of +10 in humans) is thought to disrupt electrostatic interactions and loosen microtubule attachments. Indeed, phosphorylation of the $\mathrm{Ndc} 80$ complex or the N-terminal regions of $\mathrm{Ndc} 80$ / Hecl causes a marked decrease in microtubule binding ability in vitro (Cheeseman et al. 2006; Ciferri et al. 2008; Welburn et al. 2010). In vivo, mutations to Aurora sites in the Ndc80/Hec1 tail cause either displacement from microtubules and loss of cell viability (serine to aspartic acid mutations; Guimaraes et al. 2008; Welburn et al. 2010) or errors in chromosome congression (serine to alanine mutations; Deluca et al. 2006; Welburn et al. 2010). Most studies examining tail regulation by Aurora B have largely utilized an all-or-none approach, whereby all tail sites are either altered or left alone. However, it remains possible that certain sites along the $\mathrm{Ndc} 80$ / Hec1 tail are more critical than others, or that sites are phosphorylated in a spatial or temporal fashion. One speculative model would be for the tail to exist in various states of phosphorylation: a fully phosphorylated tail would completely disengage from microtubules (error correction), while a partially phosphorylated tail would be capable of acting as a sliding tether but not a cooperativity factor (see below and Fig. 3). It will be important for future studies to test models such as this by taking a more nuanced approach to examining Aurora regulation.

A second mechanism of $\mathrm{Ndc} 80$ regulation involves the mitotic kinase Nek2A. Nek2A phosphorylates $\mathrm{Ndc} 80 / \mathrm{Hec} 1$ in vitro on a serine located in the CHD region (Chen et al. 2002; Du et al. 2008). Replacing this serine with an alanine leads to decreased microtubule binding in vitro and defects in chromosome congression in vivo. Conversely, mutating this serine to glutamic acid increases the affinity of $\mathrm{Hec} 1$ for microtubules in vitro (Du et al. 2008). This serine is located adjacent to a CHD "toe" lysine (K166), which in humans is highly important for microtubule binding both in vitro (Ciferri et al. 2008; Alushin et al. 2010) and in vivo (our unpublished data). Replacing that lysine with a glutamic acid severely reduces binding. It remains puzzling why the addition of a negative charge on neighboring amino acids yields such disparate effects on microtubule binding.

Regulation of the Ndc80 complex may be more elaborate than first envisioned. In the future, it will be important for studies to delineate the timing of individual regulatory steps. Such information will also need to be integrated with the physical shifts that the Ndc80 complex undergoes in the kinetochore in response to various stages of microtubule attachment (see below).

\section{A model for Ndc80 function}

Kinetochores need to bind microtubules tight enough to move chromosomes, but these attachments must be highly dynamic to allow flux when K-fiber microtubules treadmill towards the spindle poles (Joglekar et al. 2010). This requirement suggests that the microtubule attachment might act as a slip-clutch, which alternates between a tight binding and a slipping mode. Tight and weak binding could be generated by the regulation of cooperativity, although there is an apparent conflict for how a microtubule might flux if the Ndc80 complex only releases microtubules in response to curvature changes that accompany depolymerization. A classic theoretical model suggested that the attachment was generated through numerous low affinity interactions. The "Hill sleeve" model envisioned a number of low-affinity microtubule binding activities residing in the kinetochore sleeve (Hill 1985). These interactions could 


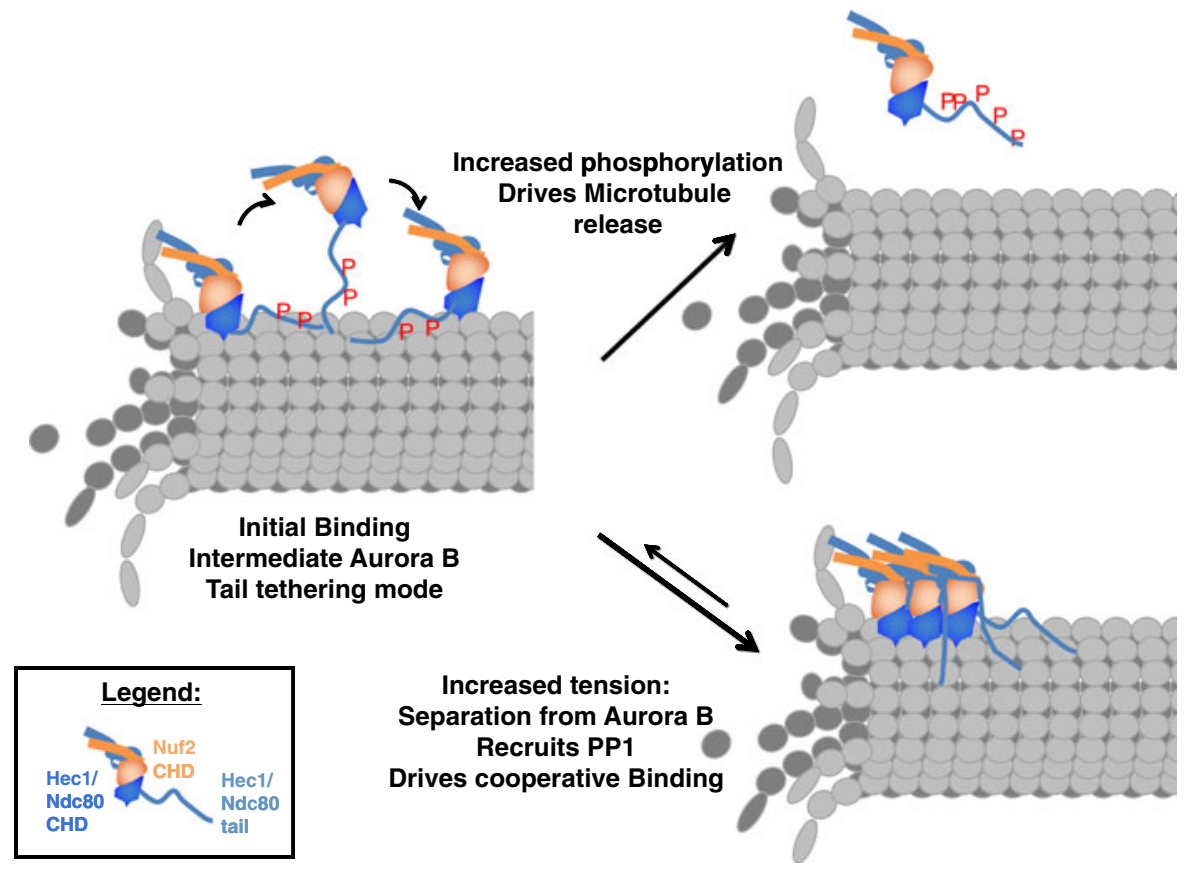

Fig. 3 Model for differential Ndc80/Hec1 tail phosphorylation. Proposed model whereby differential phosphorylation states confer distinct functions to the $\mathrm{Ndc} 80 / \mathrm{Hecl}$ unstructured tail. Left, during initial binding reactions, the Ndc80/ $\mathrm{Hec} 1$ tail is partially phosphorylated by the Aurora B kinase - creating a situation where the tail is competent to interact with tubulin E-hooks but is deficient in cooperative binding (tail tethering mode). Following initial interactions with

easily be broken and remade as the kinetochore moved along the surface of a microtubule. When a microtubule depolymerizes (and a set of attachment points are lost), there are still numerous other potential attachment sites. As long as the equilibrium favors rebinding along the surface of the microtubule over complete detachment, enough attachments could be maintained on a depolymerizing microtubule to generate force. The binding characteristics of the Ndc80 complex reflect aspects of both these models. In higher eukaryotes, we propose a model whereby the $\mathrm{Ndc} 80 / \mathrm{Hec} 1$ tail converts between a sliding tether and a cooperativity factor. During initial stages of attachment, the tail functions as a tether (thereby generating "Hill sleeve binding" through numerous low-affinity interactions), allowing the kinetochore to work by biased diffusion and maintain contact with a microtubule during periods of depolymerization. As attachments mature, the tail may facilitate tighter microtubules and an increase in tension applied to kinetochores (below right), the tail is moved away from Aurora B. This, along with recruitment of PP1 to kinetochores, results in complete tail dephosphorylation and allows formation of cooperative interactions between Ndc80 complexes. During error correction (top right), the tail becomes highly phosphorylated and can neither tether Ndc80 to microtubules nor drive cooperativity

binding by linking adjacent complexes along a microtubule protofilament. This conversion between low and high affinity would likely be regulated by the Aurora B kinase. As outlined above, cooperativity in unphosphorylated $\mathrm{Ndc} 80 / \mathrm{Hec} 1$ would allow the CHD to bind a microtubule tightly but then release in response to microtubule depolymerization. In an Ndc80 complex where the tail is phosphorylated, the CHD may bind less tightly and act more like a slipclutch.

It is important to note that in vitro, the yeast Dam1 and vertebrate Skal complexes bind microtubules with a higher affinity than the Ndc 80 complex and are also more processive than the Ndc80 complex in depolymerization-coupled movement assays (Asbury et al. 2006; Welburn et al. 2009). This has led to the assertion that these complexes, and not Ndc80, are the key couplers at the kinetochore. While the in vitro data are compelling (and it is likely that both 
complexes contribute to depolymerization-coupled movement), we must emphasize that the $\mathrm{Ndc} 80$ complex is the only proposed coupler which is absolutely required for chromosome movements in vivo in all eukaryotes. We currently favor a model whereby budding yeast and vertebrate kinetochores use distinct mechanisms to couple to microtubules. This subject will be addressed later in this review.

\section{Ndc80 complex as an integrator of kinetochore function}

The conserved kinetochore parts list is likely nearing completion, and tremendous progress has been made to define the physical connections and dependencies that exist during kinetochore assembly (Cheeseman and Desai 2008; Gascoigne and Cheeseman 2010). However, we are only beginning to fully appreciate how dynamic this large kinetochore structure can be. A great challenge moving forward will be to tease apart why the vertebrate kinetochore relies on more than 100 proteins to facilitate accurate chromosome segregation, and how microtubule binding is linked to error correction and checkpoint signaling. The Ndc80 complex has been implicated in all three aspects of kinetochore function, but it clearly does not act alone. Therefore, we must better understand how this microtubule coupler operates within the everchanging kinetochore microenvironment.

Within the kinetochore, the Ndc80 complex exists as part of a larger super-complex, often referred to as the KMN network (Kline-Smith et al. 2005; Cheeseman et al. 2006). Consisting of the four-member Ndc80 complex, the four-member Mis12 complex, KNL-1, and Zwint (in most species), this conserved network serves as the core microtubule attachment site at the kinetochore. $\mathrm{KMN}$ is brought to centromeres via links with CENP-A and CENP-C (Santaguida and Musacchio 2009). The Ndc80 complex is integrated into KMN by binding the Nsl-1 subunit of the Mis 12 complex (Petrovic et al. 2010). It has also been shown to depend on KNL-1 and the CENP/H/I/K complex for kinetochore recruitment, though differences exist between species (Desai et al. 2003; Okada et al. 2006; Cheeseman et al. 2008). Members of the KMN complex, in turn, serve as a platform for recruiting additional outer kinetochore components. The Ndc80 complex is required for kinetochore localization of the Ska and RanGAP/RanBP2 complexes, both of which are implicated in chromosome congression and checkpoint signaling (Joseph et al. 2004; Hanisch et al. 2006; Ohta et al. 2010). It is also required to bring the checkpoint proteins Mad1, Mad2, and MPS1 to the kinetochore (Martin-Lluesma et al. 2002; Deluca et al. 2003; Hori et al. 2003; McCleland et al. 2003; Meraldi et al. 2004). (Notably, no strong physical interactions have been detected between any of these proteins and the Ndc80 complex.) KNL-1 is responsible for bringing a separate set of proteins to the kinetochore. These proteins include Zwint, RZZ, Spindly, Dynein, Bub1, Bub3, BubR1, and PP1 (Desai et al. 2003; Kiyomitsu et al. 2007; Gassmann et al. 2008; Liu et al. 2010). The Mis12 complex, the final member of KMN, serves as the bridge linking Ndc80 and KNL-1 (Petrovic et al. 2010). Therefore, the outer kinetochore which emanates from the KMN network can be thought of as containing two "branches"-one assembled by KNL-1 and the other by the $\mathrm{Ndc} 80$ complex (Wan et al. 2009; Maresca and Salmon 2010; Fig. 4).

Recent work has demonstrated that the two branches are not static. A compelling study by the Salmon lab and colleagues utilized high-resolution single molecule imaging to generate a map that pinpoints the location of many proteins within the kinetochore. Importantly, this map also captures positional changes that occur in response to the loss of tension applied on kinetochores by microtubules (Wan et al. 2009). Following loss of tension, the Ndc80 complex moves backward in the kinetochore (i.e., closer to CENP-A). KNL-1 does not move nearly as far back as Ndc80 - resulting in Ndc80's position relative to KNL-1 being altered (Fig. 4). This shift may be a consequence of re-arrangements that occur between Mis12 complex members following loss of tension. Alternatively, it may indicate more centromere-proximal shifts involving the CENP-C and CENP-I proteins. Regardless, such changes demonstrate a dynamic rearrangement of the kinetochore architecture following microtubule engagement, an observation first made by electron tomography (Dong et al. 2007). It seems plausible to suggest that in addition to KNL-1, the N-terminus of $\mathrm{Ndc} 80 / \mathrm{Hec} 1$ also is being shifted in relation to RZZ and PP1, two proposed regulators of the $\mathrm{Ndc} 80$ complex that are recruited to this region of the kinetochore (Gassmann et al. 2008, 2010; Liu et al. 2010). Further experi- 


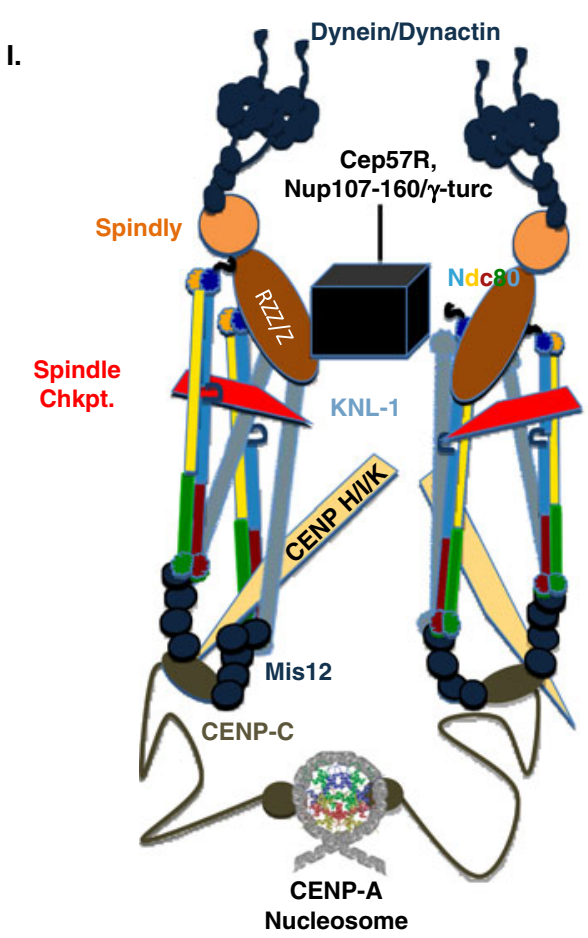

Fig. 4 The vertebrate Ndc80 complex integrated into the overall kinetochore architecture. I Prior to microtubule attachment, the overall vertebrate kinetochore architecture is less structured and possesses a number of factors involved in the initial capture of microtubules. Here, Ndc80 complex binding is initially inhibited by the RZZ complex, and the N-terminus of KNL-1 lies in close proximity to the N-terminus of the Ndc80

ments could test this prediction and could also overlay additional proteins (such as the Ska complex) onto this map.

Another pair of elegant studies extends this concept by linking shifts in kinetochore architecture to spindle assembly checkpoint (SAC) signaling (Maresca and Salmon 2009; Uchida et al. 2009). The authors here uncover evidence of intrakinetochore stretching forces within a single kinetochore, and they present a strong argument that intrakinetochore alterations - rather than the separation of sister kinetochores - are the primary readout driving SAC signaling. The authors correlate intra-kinetochore stretch with SAC signaling (low stretch, high SAC signal and high stretch, loss of SAC signal). Remarkably, they can produce the low SAC signal even when

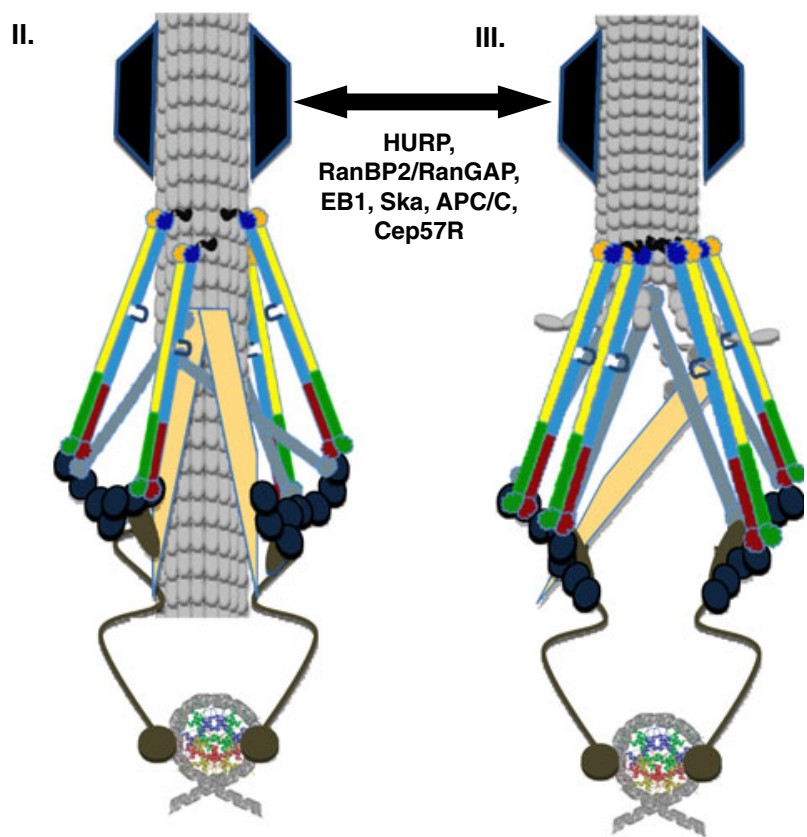

complex. II Following microtubule capture, the kinetochore becomes templated by the microtubule, and a number of tension-dependent shifts occur among kinetochore proteins. III During periods of microtubule depolymerization, CENP H/I/K binding is diminished, and Ndc80 now tracks near the end of the shortening microtubule

inter-kinetochore stretch (the separation of sister centromeres) was reduced but intra-kinetochore stretch remained elevated.

We are now beginning to better understand how the Ndc80 complex operates within the kinetochore. Based on these studies, the rough outlines can now be drawn for a model integrating microtubule engagement with checkpoint signaling. Within the outer kinetochore, there are two branches emanating from the Mis12 complex (Wan et al. 2009). The branch built by $\mathrm{Ndc} 80$ contains a number of factors implicated in microtubule binding, chromosome congression, and SAC signaling. The KNL-1 branch contains numerous checkpoint proteins but also factors which can influence the binding of $\mathrm{Ndc} 80$ to microtubules. Following kinetochore engagement 
with a microtubule, a shift occurs between the two branches. This shift has the effect of moving microtubule binders, binding regulators, and signaling modules relative to one another (Fig. 4). Such dynamic movements may also hint at multivalent docking sites for proteins such as Mad1/Mad2 and the Ska complex at the kinetochore-and could explain the inability to detect a direct interaction between the $\mathrm{Ndc} 80$ complex and any of the proteins it helps recruit (Maresca and Salmon 2010). Much of the details remain to be worked out, but in this dynamic view of the kinetochore, the Ndc80 complex emerges not only as a microtubule coupler but also as a key integrator of kinetochore signaling.

\section{Ndc80 in budding yeast vs. Hec1 in humans}

Despite its conserved presence in eukaryotic kinetochores, it remains unclear whether the Ndc80 complex has been used in the same way as species evolve. Data used to build models for Ndc80 function are often pooled from a number of divergent organisms, namely budding yeast, worms, and humans. However, kinetochore proteins are known to have evolved quite rapidly (Meraldi et al. 2006), and contradictions about Ndc80 function persist. Therefore, it is important to more carefully discern which functional elements of the Ndc80 complex have been conserved and which have evolved to meet the needs of a particular kinetochore structure. The most striking example of functional divergence involves the unstructured tail of $\mathrm{Ndc} 80 / \mathrm{Hec} 1$. In vitro, the tail is required to enhance the microtubule binding of both the yeast and human complexes (although only the metazoan complexes have been shown to exhibit cooperative binding). Additionally, recombinant yeast and human Ndc80 complex can both couple microtubule depolymerization to bead movement (Wei et al. 2007; Ciferri et al. 2008; Powers et al. 2009). However, the story is much different in vivo. While the tail is absolutely critical for kinetochore function in humans (Guimaraes et al. 2008; Miller et al. 2008), it appears dispensable in budding yeast (Kemmler et al. 2009; D. Burke
I

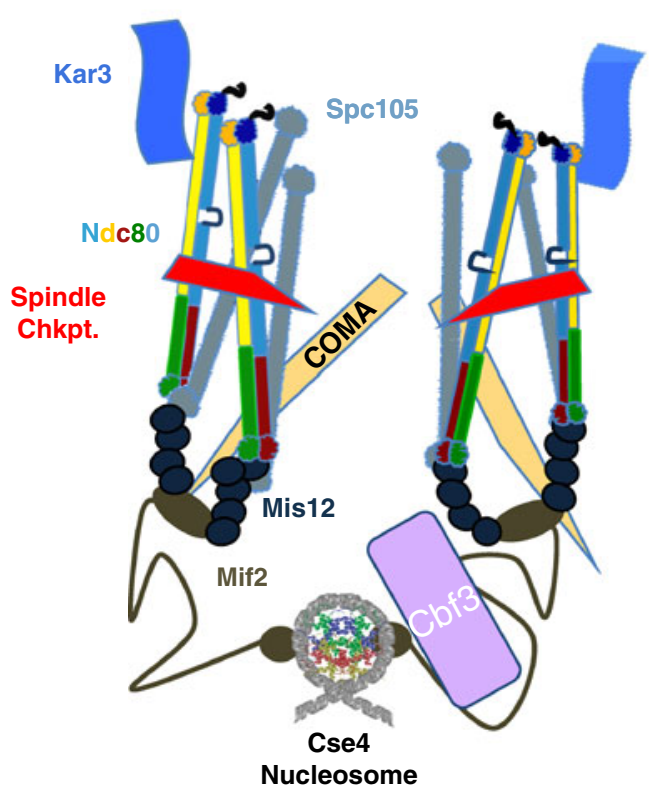

Fig. 5 The budding yeast Ndc80 complex integrated into the overall kinetochore architecture. I-III In budding yeast, many of the conserved factors remain; however, factors involved in
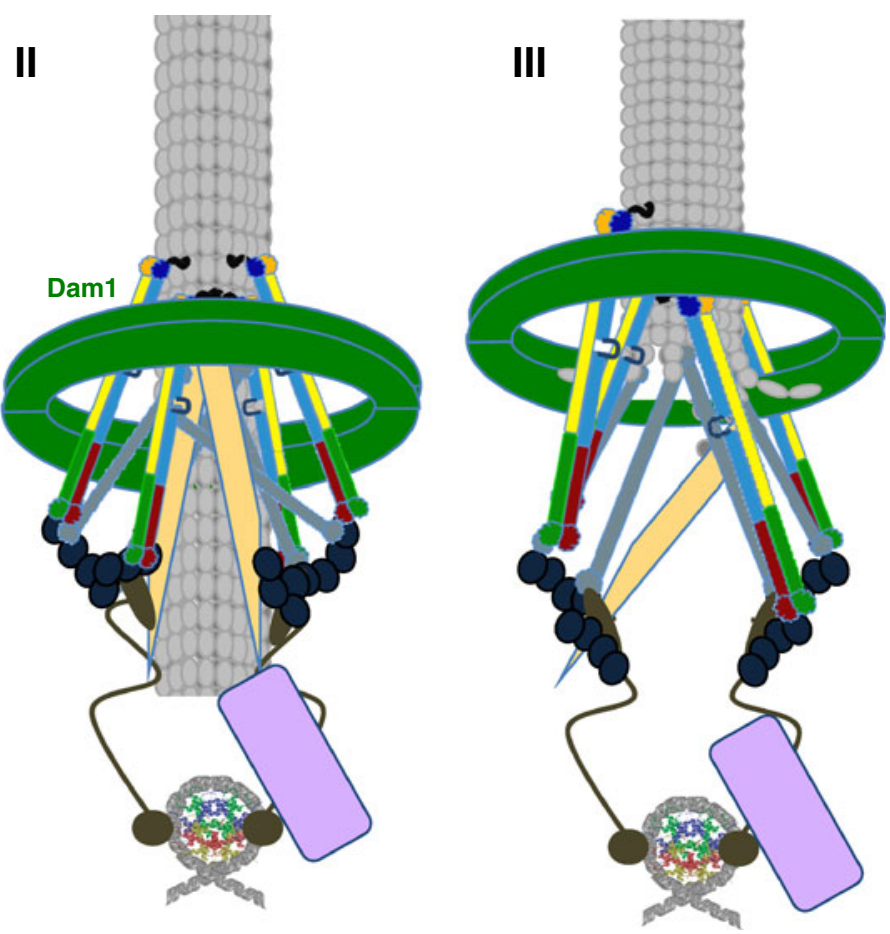

lateral attachment are distinct, and the Dam1 complex plays a primary role (through interactions with the $\mathrm{Ndc} 80$ complex) in coupling to a depolymerizing microtubule 
unpublished data). A likely explanation for such a discrepancy is the presence of the Dam 1 complex in budding yeast. The Dam1 complex can form rings around microtubules in vitro and can slide along a microtubule in response to force (Westermann et al. 2005, 2006; Asbury et al. 2006). When bound to beads, it is capable of moving cargo along a depolymerizing microtubule in a processive manner (Asbury et al. 2006; Grishchuk et al. 2008). Furthermore, free Dam1 complex flowed into an $\mathrm{Ndc} 80$ bead-based experiment can confer increased microtubule binding and processivity to the yeast $\mathrm{Ndc} 80$ complex (Tien et al. 2010; Lampert et al. 2010). Therefore, in budding yeast, the tail of $\mathrm{Ndc} 80$ may be less important because Dam1 also functions as a key kinetochore coupler. Here, the kinetochore works by a sliding mechanism, riding the conformational wave caused by a depolymerizing microtubule (Asbury et al. 2010). In contrast, the metazoan complex acts as a biased diffuser built upon low affinity charge-based interactions, using the tail and cooperative CHD binding together with conformation-dependent microtubule release (Figs. 2 and 3). An intriguing evolutionary intermediate may exist in fission yeast, where the Dam1 complex is present at kinetochores in lower amounts (Joglekar et al. 2008) and is not essential for viability (Sanchez-Perez et al. 2005; Liu et al. 2005). In this organism, however, the Dam1 complex is required to retrieve unclustered kinetochores (Franco et al. 2007). It would be interesting to know the requirements of the $\mathrm{Ndc} 80$ tail in this organism.

The question of whether a Dam1-like complex exists in vertebrates has been the subject of much study and debate. In humans, the Ska complex has emerged as a leading candidate for the functional counterpart of the Dam1 complex, but its case is not airtight. While capable of binding microtubules and moving a bead cargo (Welburn et al. 2009), it has not been demonstrated that the Ska complex can enhance Ndc80 tracking abilities in a bead-based coupling assay. Furthermore, an emerging body of data points to a prominent role for the Ska complex in kinetochore recruitment of the $\mathrm{APC} / \mathrm{C}$ and checkpoint signaling, a characteristic that has not been ascribed to Dam1 (Hanisch et al. 2006; Daum et al. 2009; Theis et al. 2009; Ohta et al. 2010).

The discrepancy over $\mathrm{Ndc} 80 / \mathrm{Hecl}$ tail function raises the question of whether other functional elements of Ndc80 may have evolved. There are potential points of divergence. For example, the mechanism of Aurora B/Ipl1-mediated error correction may also differ between species. In humans, the unstructured tail of $\mathrm{Hec} 1$ contains numerous Aurora B target sites, and mutation of these sites creates significant errors in microtubule binding both in vitro and in vivo. In budding yeast, mutation of Ipl1 siteswhile creating binding defects in vitro (Cheeseman et al. 2006) - does not appear to be as consequential in vivo (Akiyoshi et al. 2009). Ipl1 also targets numerous sites on the Dam1 complex, including a set of sites on Dam1 that disrupt the interaction between the Dam1 and Ndc80 complexes (and presumably Dam1 complex kinetochore recruitment; Shang et al. 2003; Tien et al. 2010). As mutation of these Dam1 sites creates a strong phenotype in vivo (Shang et al. 2003), it is possible that this is a more prominent means of attachment turnover in budding yeast. (Notably, Aurora B phosphorylation of the Ska complex has not been reported.) Furthermore, while MPS1 phosphorylation of the Ndc80 tail also is important in budding yeast, it is unclear whether this event is conserved across species (Kemmler et al. 2009).

A number of proteins localize to kinetochores and spindles in vertebrates but not in budding yeast (Figs. 4 and 5). These include members of the RanBP2/RanGAP complex, the Nup107-160 complex (Zuccolo et al. 2007; Mishra et al. 2010), RZZ, Spindly, Dynein, HURP (Wong and Fang 2006; Koffa et al. 2006; Sillje et al. 2006), and Cep57R (Emanuele and Stukenberg 2007). While analogous proteins may yet be identified in budding yeast (Pagliuca et al. 2009), for now, these proteins constitute a black box at the vertebrate kinetochore where relatively little is known about the precise contributions made by these factors. As many of these proteins have been implicated in aspects of chromosome congression, there is still much work to be done to understand how kinetochores couple microtubule depolymerization to chromosome movement.

\section{References}

Akiyoshi B, Nelson CR, Ranish JA, Biggins S (2009) Analysis of Ipl1-mediated phosphorylation of the Ndc80 kinetochore protein in Saccharomyces cerevisiae. Genetics 183:1591-1595 
Alushin GM, Ramey VH, Pasqualato S, Ball DA, Grigorieff N, Musacchio A, Nogales E (2010) The Ndc80 kinetochore complex forms oligomeric arrays along microtubules. Nature 467:805-810

Asbury CL, Gestaut DR, Powers AF, Franck AD, Davis TN (2006) The Dam1 kinetochore complex harnesses microtubule dynamics to produce force and movement. Proc Natl Acad Sci USA 103:9873-9878

Asbury CL, Tien JF, Davis TN (2010) Kinetochores' gripping feat: conformational wave or biased diffusion? Trends Cell Biol. doi:10.1016/j.tcb.2010.09.003

Bharadwaj R, Qi W, Yu H (2004) Identification of two novel components of the human NDC80 kinetochore complex. J Biol Chem 279:13076-13085

Cheeseman IM, Desai A (2008) Molecular architecture of the kinetochore-microtubule interface. Nat Rev Mol Cell Biol 9:33-46

Cheeseman IM, Anderson S, Jwa M, Green EM, Kang J, Yates JR III, Chan CS, Drubin DG, Barnes G (2002) Phosphoregulation of kinetochore-microtubule attachments by the Aurora kinase Ipl1p. Cell 111:163-172

Cheeseman IM, Niessen S, Anderson S, Hyndman F, Yates JR III, Oegema K, Desai A (2004) A conserved protein network controls assembly of the outer kinetochore and its ability to sustain tension. Genes Dev 18:2255-2268

Cheeseman IM, Chappie JS, Wilson-Kubalek EM, Desai A (2006) The conserved KMN network constitutes the core microtubule-binding site of the kinetochore. Cell 127:983997

Cheeseman IM, Hori T, Fukagawa T, Desai A (2008) KNL1 and the CENP-H///K complex coordinately direct kinetochore assembly in vertebrates. Mol Biol Cell 19:587-594

Chen Y, Riley DJ, Chen PL, Lee WH (1997) HEC, a novel nuclear protein rich in leucine heptad repeats specifically involved in mitosis. Mol Cell Biol 17:6049-6056

Chen Y, Riley DJ, Zheng L, Chen PL, Lee WH (2002) Phosphorylation of the mitotic regulator protein $\mathrm{Hec} 1$ by Nek2 kinase is essential for faithful chromosome segregation. J Biol Chem 277:49408-49416

Ciferri C, De Luca J, Monzani S, Ferrari KJ, Ristic D, Wyman C, Stark H, Kilmartin J, Salmon ED, Musacchio A (2005) Architecture of the human ndc80-hec1 complex, a critical constituent of the outer kinetochore. J Biol Chem 280:29088-29095

Ciferri C, Musacchio A, Petrovic A (2007) The Ndc80 complex: hub of kinetochore activity. FEBS Lett 581:2862-2869

Ciferri C, Pasqualato S, Screpanti E, Varetti G, Santaguida S, Dos RG, Maiolica A, Polka J, De Luca JG, De WP, Salek M, Rappsilber J, Moores CA, Salmon ED, Musacchio A (2008) Implications for kinetochore-microtubule attachment from the structure of an engineered Ndc80 complex. Cell 133:427-439

Cleveland DW, Mao Y, Sullivan KF (2003) Centromeres and kinetochores: from epigenetics to mitotic checkpoint signaling. Cell 112:407-421

Daum JR, Wren JD, Daniel JJ, Sivakumar S, McAvoy JN, Potapova TA, Gorbsky GJ (2009) Ska3 is required for spindle checkpoint silencing and the maintenance of chromosome cohesion in mitosis. Curr Biol 19:1467-1472
Deluca JG, Moree B, Hickey JM, Kilmartin JV, Salmon ED (2002) hNuf2 inhibition blocks stable kinetochoremicrotubule attachment and induces mitotic cell death in HeLa cells. J Cell Biol 159:549-555

Deluca JG, Howell BJ, Canman JC, Hickey JM, Fang G, Salmon ED (2003) Nuf2 and $\mathrm{Hecl}$ are required for retention of the checkpoint proteins $\mathrm{Mad} 1$ and $\operatorname{Mad} 2$ to kinetochores. Curr Biol 13:2103-2109

Deluca JG, Dong Y, Hergert P, Strauss J, Hickey JM, Salmon ED, McEwen BF (2005) Hec1 and Nuf2 are core components of the kinetochore outer plate essential for organizing microtubule attachment sites. Mol Biol Cell 16:519-531

Deluca JG, Gall WE, Ciferri C, Cimini D, Musacchio A, Salmon ED (2006) Kinetochore microtubule dynamics and attachment stability are regulated by Hec1. Cell 127:969-982

Desai A, Rybina S, Muller-Reichert T, Shevchenko A, Shevchenko A, Hyman A, Oegema K (2003) KNL-1 directs assembly of the microtubule-binding interface of the kinetochore in C. elegans. Genes Dev 17:2421-2435

Dong Y, Vanden Beldt KJ, Meng X, Khodjakov A, McEwen BF (2007) The outer plate in vertebrate kinetochores is a flexible network with multiple microtubule interactions. Nat Cell Biol 9:516-522

Du J, Cai X, Yao J, Ding X, Wu Q, Pei S, Jiang K, Zhang Y, Wang W, Shi Y, Lai Y, Shen J, Teng M, Huang H, Fei Q, Reddy ES, Zhu J, Jin C, Yao X (2008) The mitotic checkpoint kinase NEK2A regulates kinetochore microtubule attachment stability. Oncogene 27:4107-4114

Emanuele MJ, Stukenberg PT (2007) Xenopus Cep57 is a novel kinetochore component involved in microtubule attachment. Cell 130:893-905

Franco A, Meadows JC, Millar JB (2007) The Dam1/DASH complex is required for the retrieval of unclustered kinetochores in fission yeast. J Cell Sci 120:3345-3351

Gascoigne KE, Cheeseman IM (2010) Kinetochore assembly: if you build it, they will come. Curr Opin Cell Biol. doi:10.1016/j.ceb.2010.07.007

Gassmann R, Essex A, Hu JS, Maddox PS, Motegi F, Sugimoto A, O'Rourke SM, Bowerman B, McLeod I, Yates JR III, Oegema K, Cheeseman IM, Desai A (2008) A new mechanism controlling kinetochore-microtubule interactions revealed by comparison of two dynein-targeting components: SPDL-1 and the Rod/Zwilch/Zw10 complex. Genes Dev 22:2385-2399

Gassmann R, Holland AJ, Varma D, Wan X, Civril F, Cleveland DW, Oegema K, Salmon ED, Desai A (2010) Removal of spindly from microtubule-attached kinetochores controls spindle checkpoint silencing in human cells. Genes Dev 24:957-971

Grishchuk EL, Efremov AK, Volkov VA, Spiridonov IS, Gudimchuk N, Westermann S, Drubin D, Barnes G, McIntosh JR, Ataullakhanov FI (2008) The Dam1 ring binds microtubules strongly enough to be a processive as well as energy-efficient coupler for chromosome motion. Proc Natl Acad Sci USA 105:15423-15428

Guimaraes GJ, Dong Y, McEwen BF, Deluca JG (2008) Kinetochore-microtubule attachment relies on the disordered N-terminal tail domain of Hec1. Curr Biol 18:17781784 
Hanisch A, Sillje HH, Nigg EA (2006) Timely anaphase onset requires a novel spindle and kinetochore complex comprising Ska1 and Ska2. EMBO J 25:5504-5515

Hill TL (1985) Theoretical problems related to the attachment of microtubules to kinetochores. Proc Natl Acad Sci USA 82:4404-4408

Hori T, Haraguchi T, Hiraoka Y, Kimura H, Fukagawa T (2003) Dynamic behavior of Nuf2-Hec1 complex that localizes to the centrosome and centromere and is essential for mitotic progression in vertebrate cells. J Cell Sci 116:3347-3362

Howell BJ, McEwen BF, Canman JC, Hoffman DB, Farrar EM, Rieder CL, Salmon ED (2001) Cytoplasmic dynein/ dynactin drives kinetochore protein transport to the spindle poles and has a role in mitotic spindle checkpoint inactivation. J Cell Biol 155:1159-1172

Janke C, Ortiz J, Lechner J, Shevchenko A, Shevchenko A, Magiera MM, Schramm C, Schiebel E (2001) The budding yeast proteins Spc24p and Spc25p interact with $\mathrm{Ndc} 80 \mathrm{p}$ and Nuf2p at the kinetochore and are important for kinetochore clustering and checkpoint control. EMBO J 20:777-791

Joglekar AP, Bouck DC, Molk JN, Bloom KS, Salmon ED (2006) Molecular architecture of a kinetochoremicrotubule attachment site. Nat Cell Biol 8:581-585

Joglekar AP, Bouck D, Finley K, Liu X, Wan Y, Berman J, He X, Salmon ED, Bloom KS (2008) Molecular architecture of the kinetochore-microtubule attachment site is conserved between point and regional centromeres. J Cell Biol 181:587-594

Joglekar AP, Bloom KS, Salmon ED (2010) Mechanisms of force generation by end-on kinetochore-microtubule attachments. Curr Opin Cell Biol 22:57-67

Johnston K, Joglekar A, Hori T, Suzuki A, Fukagawa T, Salmon ED (2010) Vertebrate kinetochore protein architecture: protein copy number. J Cell Biol 189:937-943

Joseph J, Liu ST, Jablonski SA, Yen TJ, Dasso M (2004) The RanGAP1-RanBP2 complex is essential for microtubulekinetochore interactions in vivo. Curr Biol 14:611-617

Kemmler S, Stach M, Knapp M, Ortiz J, Pfannstiel J, Ruppert T, Lechner J (2009) Mimicking Ndc80 phosphorylation triggers spindle assembly checkpoint signalling. EMBO J 28:1099-1110

Kiyomitsu T, Obuse C, Yanagida M (2007) Human Blinkin/ AF $15 \mathrm{q} 14$ is required for chromosome alignment and the mitotic checkpoint through direct interaction with Bub1 and BubR1. Dev Cell 13:663-676

Kline-Smith SL, Sandall S, Desai A (2005) Kinetochorespindle microtubule interactions during mitosis. Curr Opin Cell Biol 17:35-46

Koffa MD, Casanova CM, Santarella R, Kocher T, Wilm M, Mattaj IW (2006) HURP is part of a Ran-dependent complex involved in spindle formation. Curr Biol 16:743754

Koshland DE, Mitchison TJ, Kirschner MW (1988) Polewards chromosome movement driven by microtubule depolymerization in vitro. Nature 331:499-504

Lampert F, Hornung P, Westermann S (2010) The Dam1 complex confers microtubule plus end-tracking activity to the Ndc80 kinetochore complex. J Cell Biol 189:641-649
Liu X, McLeod I, Anderson S, Yates JR III, He X (2005) Molecular analysis of kinetochore architecture in fission yeast. EMBO J 24:2919-2930

Liu D, Vader G, Vromans MJ, Lampson MA, Lens SM (2009) Sensing chromosome bi-orientation by spatial separation of aurora B kinase from kinetochore substrates. Science 323:1350-1353

Liu D, Vleugel M, Backer CB, Hori T, Fukagawa T, Cheeseman IM, Lampson MA (2010) Regulated targeting of protein phosphatase 1 to the outer kinetochore by KNL1 opposes Aurora B kinase. J Cell Biol 188:809-820

Maiolica A, Cittaro D, Borsotti D, Sennels L, Ciferri C, Tarricone C, Musacchio A, Rappsilber J (2007) Structural analysis of multiprotein complexes by cross-linking, mass spectrometry, and database searching. Mol Cell Proteomics 6:2200-2211

Maresca TJ, Salmon ED (2009) Intrakinetochore stretch is associated with changes in kinetochore phosphorylation and spindle assembly checkpoint activity. J Cell Biol 184:373-381

Maresca TJ, Salmon ED (2010) Welcome to a new kind of tension: translating kinetochore mechanics into a waitanaphase signal. J Cell Sci 123:825-835

Martin-Lluesma S, Stucke VM, Nigg EA (2002) Role of Hec1 in spindle checkpoint signaling and kinetochore recruitment of Mad1/Mad2. Science 297:2267-2270

McCleland ML, Gardner RD, Kallio MJ, Daum JR, Gorbsky GJ, Burke DJ, Stukenberg PT (2003) The highly conserved Ndc80 complex is required for kinetochore assembly, chromosome congression, and spindle checkpoint activity. Genes Dev 17:101-114

McCleland ML, Kallio MJ, Barrett-Wilt GA, Kestner CA, Shabanowitz J, Hunt DF, Gorbsky GJ, Stukenberg PT (2004) The vertebrate Ndc80 complex contains Spc24 and Spc25 homologs, which are required to establish and maintain kinetochore-microtubule attachment. Curr Biol 14:131-137

McIntosh JR, Grishchuk EL, Morphew MK, Efremov AK, Zhudenkov K, Volkov VA, Cheeseman IM, Desai A, Mastronarde DN, Ataullakhanov FI (2008) Fibrils connect microtubule tips with kinetochores: a mechanism to couple tubulin dynamics to chromosome motion. Cell 135:322333

Meraldi P, Draviam VM, Sorger PK (2004) Timing and checkpoints in the regulation of mitotic progression. Dev Cell 7:45-60

Meraldi P, McAinsh AD, Rheinbay E, Sorger PK (2006) Phylogenetic and structural analysis of centromeric DNA and kinetochore proteins. Genome Biol 7:R23

Miller SA, Johnson ML, Stukenberg PT (2008) Kinetochore attachments require an interaction between unstructured tails on microtubules and $\mathrm{Ndc} 80(\mathrm{Hec} 1)$. Curr Biol 18:1785-1791

Mishra RK, Chakraborty P, Arnaoutov A, Fontoura BM, Dasso M (2010) The Nup107-160 complex and gamma-TuRC regulate microtubule polymerization at kinetochores. Nat Cell Biol 12:164-169

Musacchio A, Salmon ED (2007) The spindle-assembly checkpoint in space and time. Nat Rev Mol Cell Biol 8:379-393 
Ohta S, Bukowski-Wills JC, Sanchez-Pulido L, Alves FL, Wood L, Chen ZA, Platani M, Fischer L, Hudson DF, Ponting CP, Fukagawa T, Earnshaw WC, Rappsilber J (2010) The protein composition of mitotic chromosomes determined using multiclassifier combinatorial proteomics. Cell 142:810-821

Okada M, Cheeseman IM, Hori T, Okawa K, McLeod IX, Yates JR III, Desai A, Fukagawa T (2006) The CENP-H-I complex is required for the efficient incorporation of newly synthesized CENP-A into centromeres. Nat Cell Biol 8:446-457

Osborne MA, Schlenstedt G, Jinks T, Silver PA (1994) Nuf2, a spindle pole body-associated protein required for nuclear division in yeast. J Cell Biol 125:853-866

Pagliuca C, Draviam VM, Marco E, Sorger PK, De WP (2009) Roles for the conserved $\mathrm{spc} 105 \mathrm{p} / \mathrm{kre} 28 \mathrm{p}$ complex in kinetochore-microtubule binding and the spindle assembly checkpoint. PLoS ONE 4:e7640

Petrovic A, Pasqualato S, Dube P, Krenn V, Santaguida S, Cittaro D, Monzani S, Massimiliano L, Keller J, Tarricone A, Maiolica A, Stark H, Musacchio A (2010) The MIS12 complex is a protein interaction hub for outer kinetochore assembly. J Cell Biol 190:835-852

Powers AF, Franck AD, Gestaut DR, Cooper J, Gracyzk B, Wei RR, Wordeman L, Davis TN, Asbury CL (2009) The Ndc80 kinetochore complex forms load-bearing attachments to dynamic microtubule tips via biased diffusion. Cell 136:865-875

Putkey FR, Cramer T, Morphew MK, Silk AD, Johnson RS, McIntosh JR, Cleveland DW (2002) Unstable kinetochoremicrotubule capture and chromosomal instability following deletion of CENP-E. Dev Cell 3:351-365

Ruchaud S, Carmena M, Earnshaw WC (2007) Chromosomal passengers: conducting cell division. Nat Rev Mol Cell Biol 8:798-812

Sanchez-Perez I, Renwick SJ, Crawley K, Karig I, Buck V, Meadows JC, Franco-Sanchez A, Fleig U, Toda T, Millar JB (2005) The DASH complex and Klp5/Klp6 kinesin coordinate bipolar chromosome attachment in fission yeast. EMBO J 24:2931-2943

Santaguida S, Musacchio A (2009) The life and miracles of kinetochores. EMBO J 28:2511-2531

Shang C, Hazbun TR, Cheeseman IM, Aranda J, Fields S, Drubin DG, Barnes G (2003) Kinetochore protein interactions and their regulation by the aurora kinase Ipllp. Mol Biol Cell 14:3342-3355

Sillje HH, Nagel S, Korner R, Nigg EA (2006) HURP is a Ranimportin beta-regulated protein that stabilizes kinetochore microtubules in the vicinity of chromosomes. Curr Biol 16:731-742

Sjoblom B, Ylanne J, Djinovic-Carugo K (2008) Novel structural insights into F-actin-binding and novel functions of calponin homology domains. Curr Opin Struct Biol 18:702-708

Stukenberg PT, Foltz DR (2010) Kinetochores: orchestrating the chromosomal minuet. Curr Biol 20:R522-R525

Tanaka TU, Desai A (2008) Kinetochore-microtubule interactions: the means to the end. Curr Opin Cell Biol 20:53-63

Theis M, Slabicki M, Junqueira M, Paszkowski-Rogacz M, Sontheimer J, Kittler R, Heninger AK, Glatter T, Kruusmaa K, Poser I, Hyman AA, Pisabarro MT, Gstaiger M,
Aebersold R, Shevchenko A, Buchholz F (2009) Comparative profiling identifies $\mathrm{C} 13$ orf 3 as a component of the Ska complex required for mammalian cell division. EMBO J 28:1453-1465

Tien JF, Umbreit NT, Gestaut DR, Franck AD, Cooper J, Wordeman L, Gonen T, Asbury CL, Davis TN (2010) Cooperation of the Dam1 and Ndc80 kinetochore complexes enhances microtubule coupling and is regulated by aurora B. J Cell Biol 189:713-723

Uchida KS, Takagaki K, Kumada K, Hirayama Y, Noda T, Hirota T (2009) Kinetochore stretching inactivates the spindle assembly checkpoint. J Cell Biol 184:383-390

Wan X, O'Quinn RP, Pierce HL, Joglekar AP, Gall WE, Deluca JG, Carroll CW, Liu ST, Yen TJ, McEwen BF, Stukenberg PT, Desai A, Salmon ED (2009) Protein architecture of the human kinetochore microtubule attachment site. Cell 137:672-684

Wang HW, Long S, Ciferri C, Westermann S, Drubin D, Barnes G, Nogales E (2008) Architecture and flexibility of the yeast Ndc80 kinetochore complex. J Mol Biol 383:894903

Wei RR, Sorger PK, Harrison SC (2005) Molecular organization of the Ndc80 complex, an essential kinetochore component. Proc Natl Acad Sci USA 102:5363-5367

Wei RR, Schnell JR, Larsen NA, Sorger PK, Chou JJ, Harrison SC (2006) Structure of a central component of the yeast kinetochore: the Spc24p/Spc25p globular domain. Structure 14:1003-1009

Wei RR, Al Bassam J, Harrison SC (2007) The Ndc80/HEC1 complex is a contact point for kinetochore-microtubule attachment. Nat Struct Mol Biol 14:54-59

Welburn JP, Grishchuk EL, Backer CB, Wilson-Kubalek EM, Yates JR III, Cheeseman IM (2009) The human kinetochore Ska1 complex facilitates microtubule depolymerizationcoupled motility. Dev Cell 16:374-385

Welburn JP, Vleugel M, Liu D, Yates JR III, Lampson MA, Fukagawa T, Cheeseman IM (2010) Aurora B phosphorylates spatially distinct targets to differentially regulate the kinetochore-microtubule interface. Mol Cell 38:383-392

Westermann S, Avila-Sakar A, Wang HW, Niederstrasser H, Wong J, Drubin DG, Nogales E, Barnes G (2005) Formation of a dynamic kinetochore- microtubule interface through assembly of the Dam1 ring complex. Mol Cell 17:277-290

Westermann S, Wang HW, vila-Sakar A, Drubin DG, Nogales E, Barnes G (2006) The Dam1 kinetochore ring complex moves processively on depolymerizing microtubule ends. Nature 440:565-569

Wigge PA, Kilmartin JV (2001) The Ndc80p complex from Saccharomyces cerevisiae contains conserved centromere components and has a function in chromosome segregation. J Cell Biol 152:349-360

Wigge PA, Jensen ON, Holmes S, Soues S, Mann M, Kilmartin JV (1998) Analysis of the Saccharomyces spindle pole by matrix-assisted laser desorption/ionization (MALDI) mass spectrometry. J Cell Biol 141:967-977

Wilson-Kubalek EM, Cheeseman IM, Yoshioka C, Desai A, Milligan RA (2008) Orientation and structure of the Ndc80 complex on the microtubule lattice. J Cell Biol 182:1055-1061 
Wong J, Fang G (2006) HURP controls spindle dynamics to promote proper interkinetochore tension and efficient kinetochore capture. J Cell Biol 173:879-891

Wordeman L, Steuer ER, Sheetz MP, Mitchison T (1991) Chemical subdomains within the kinetochore domain of isolated CHO mitotic chromosomes. J Cell Biol 114:285-294

Yen TJ, Li G, Schaar BT, Szilak I, Cleveland DW (1992) CENP-E is a putative kinetochore motor that accumulates just before mitosis. Nature 359:536-539
Zimniak T, Stengl K, Mechtler K, Westermann S (2009) Phosphoregulation of the budding yeast EB1 homologue Bim1p by Aurora/Ipl1p. J Cell Biol 186:379391

Zuccolo M, Alves A, Galy V, Bolhy S, Formstecher E, Racine V, Sibarita JB, Fukagawa T, Shiekhattar R, Yen T, Doye V (2007) The human Nup107-160 nuclear pore subcomplex contributes to proper kinetochore functions. EMBO J 26:1853-1864 